\title{
Review \\ Bench-to-bedside review: The initial hemodynamic resuscitation of the septic patient according to Surviving Sepsis Campaign guidelines - does one size fit all?
}

\author{
Azriel Perel \\ Department of Anesthesiology and Intensive Care, Sheba Medical Center, Tel Aviv University, Tel Hashomer, 52621 Israel
}

Corresponding author: Azriel Perel, perelao@shani.net

Critical Care 2008, 12:223 (doi:10.1186/cc6979)

This article is online at http://ccforum.com/content/12/5/223

Critical Care 2008, $12: 223$ (doi:10.1186/cc6979)

(c) 2008 BioMed Central Ltd

\begin{abstract}
The Surviving Sepsis Campaign guidelines for the management of severe sepsis and septic shock recommend that the initial hemodynamic resuscitation be done according to the protocol used by Rivers and colleagues in their well-known early goaldirected therapy (EGDT) study. However, it may well be that their patients were much sicker on admission than many other septic patients. Compared with other populations of septic patients, the patients of Rivers and colleagues had a higher incidence of severe comorbidities, a more severe hemodynamic status on admission (excessively low central venous oxygen saturation $\left[\mathrm{ScvO}_{2}\right]$, low central venous pressure [CVP], and high lactate), and higher mortality rates. Therefore, it may well be that these patients arrived to the hospital in late untreated hypovolemic sepsis, which may have been due, in part at least, to low socioeconomic status and reduced access to health care. The EGDT protocol uses target values for CVP and $\mathrm{ScvO}_{2}$ to guide hemodynamic management. However, filling pressures do not reliably predict the response to fluid administration, while the $\mathrm{ScvO}_{2}$ of septic patients is characteristically high due to decreased oxygen extraction. For all these reasons, it seems that the hemodynamic component of the Surviving Sepsis Campaign guidelines cannot be applied to all septic patients, particularly those who develop sepsis during their hospital stay.
\end{abstract}

\section{Background}

The early institution of goal-directed therapy has always been perceived as a key factor for the successful management of critically ill patients. In trauma patients, for example, the early detection of occult hypoperfusion and its correction using goal-directed therapy have been shown to reduce both mortality and morbidity [1]. Nevertheless, the 2001 study by Rivers and colleagues [2] (referred to hereafter as 'the Rivers study') was the first to show that the institution of early goaldirected therapy (EGDT) upon admission to the emergency department (ED) can significantly reduce mortality of patients in severe sepsis or septic shock. The results of the Rivers study are unique because, due to the complexity of hemodynamics in sepsis, the goals of therapy are much more difficult to define with certainty than in other forms of shock [3]. A recent systematic literature review has indeed found a lack of agreement on hemodynamic goals for management of patients with sepsis, proposing that this lack of consistency may contribute to heterogeneity in treatment effects for clinical trials of novel sepsis therapies [4]. Although the challenge of overcoming sepsis has previously prompted the production of practice parameters for hemodynamic support of adult septic patients [3], no evidence has been produced, prior to the Rivers study, that adherence to any such treatment guidelines can improve the dismal prognosis of severe sepsis and septic shock.

Following the Rivers study, critical care and infectious disease experts representing 11 international organizations developed management guidelines for severe sepsis and septic shock under the auspices of the Surviving Sepsis Campaign (SSC) [5]. These guidelines have received worldwide acclaim for being 'a noble, well-intentioned approach to transfer knowledge gained from research into practice at the bedside' [6]. The SSC guidelines were adopted by many medical centers worldwide, a process that is still ongoing and that has led to numerous reports of improved survival [7]. The uncontested success of these guidelines has led to their inclusion in mainstream reviews on the management of sepsis [8] and made opinion leaders recommend that they be adopted by the complete health care network involved in the management of patients with severe sepsis [9].

However, in addition to the recommendations for the initial hemodynamic resuscitation of the septic patient which are

ARDS = acute respiratory distress syndrome; $C V P=$ central venous pressure; $E D=$ emergency department; EGDT = early goal-directed therapy; $\mathrm{ICU}=$ intensive care unit; $\mathrm{PAOP}=$ pulmonary artery occlusion pressure; $\mathrm{ScvO}_{2}=$ central venous oxygen saturation; $\mathrm{SSC}=\mathrm{Surviving}$ Sepsis Campaign. 
Table 1

The Surviving Sepsis Campaign protocol for the initial hemodynamic resuscitation in severe sepsis and septic shock (adopted from [10])

Begin resuscitation immediately in patients with hypotension or elevated serum lactate of greater than $4 \mathrm{mmol} / \mathrm{L}$, using either crystalloids or colloids. Give fluid challenges of $1,000 \mathrm{~mL}$ of crystalloids or 300 to $500 \mathrm{~mL}$ of colloids over the course of 30 minutes. More rapid and larger volumes may be required in sepsis-induced tissue hypoperfusion.

Resuscitation goals include the following:

Central venous pressure (CVP) of 8 to $12 \mathrm{~mm} \mathrm{Hg}$. A higher target CVP of 12 to $15 \mathrm{~mm} \mathrm{Hg}$ is recommended in the presence of mechanical ventilation or pre-existing decreased ventricular compliance.

Mean arterial pressure of greater than or equal to $65 \mathrm{~mm} \mathrm{Hg}$

Urine output of greater than or equal to $0.5 \mathrm{~mL} / \mathrm{kg}$ per hour

Central venous (superior vena cava) oxygen saturation $\left(\mathrm{ScvO}_{2}\right)$ of greater than or equal to $70 \%$ or mixed venous oxygen saturation $(\mathrm{SvO})$ of greater than or equal to $65 \%$.

If venous $\mathrm{O}_{2}$ saturation target is not achieved, consider further fluid, transfuse packed red blood cells if required to hematocrit of greater than or equal to $30 \%$, and/or start dobutamine infusion.

based on the Rivers protocol (Table 1), the SSC guidelines include many other aspects of care, including the early use of antibiotics, tight glucose control, steroids, recombinant human-activated protein $\mathrm{C}$, and many more. In the most recent edition of these guidelines [10], the number of recommendations increased to 85 from the original 52 that appeared in the 2004 edition [11]. A close look at all of the reports of decreasing mortality following the adoption of the SSC guidelines [7] reveals that, in all of them, all aspects of the SSC guidelines have been implemented, and not just the hemodynamic protocol. The reduction in mortality following the implementation of these guidelines therefore may be attributed, in part at least, to the early initiation of effective antimicrobial therapy, which has been shown to play a major role in sepsis outcome [12]. The growing number of reports attesting to the success of the SSC guidelines therefore cannot serve as evidence that the initial hemodynamic resuscitation 'bundle', in and by itself, leads to better survival [13]. In addition, the Rivers single-center study has never been repeated and is therefore the only evidence for the effectiveness of the hemodynamic protocol that is now being recommended for all hypotensive and/or hyperlactatemic septic patients, both in and outside the ED. Our reservations about the inclusion of the Rivers protocol (Table 1) in the SSC guidelines are based on its perceived physiological flaws and on the possibility that the patients of the Rivers study do not represent all septic patients.

\section{Do the Rivers patients represent all septic patients?}

One of the most outstanding findings of the Rivers study is that the mean central venous oxygen saturation $\left(\mathrm{ScvO}_{2}\right)$ on admission to the ED was less than $50 \%$ in both the standard therapy and the EGDT groups [2]. These $\mathrm{ScvO}_{2}$ values are extremely low since the normal $\mathrm{ScvO}_{2}$ is about $75 \%$. Moreover, in septic patients, the $\mathrm{ScvO}_{2}$ is mainly normal or even supranormal due to a reduced oxygen extraction ratio, which is characteristic of septic shock [14,15]. Recent studies have indeed found much higher $\mathrm{ScvO}_{2}$ values in septic shock patients either in the ED or on admission to the intensive care unit (ICU) [16-18]. In two of these studies $[17,18]$, the mean $\mathrm{ScvO}_{2}$ was $72 \%$ to $74 \%$; in one of them [18], only 8 out of 125 patients $(6 \%)$ had an $\mathrm{ScvO}_{2}$ value below $60 \%$ and only 1 patient had an $\mathrm{ScvO}_{2}$ below $50 \%$. The septic patients in these studies were also different than the Rivers patients in that the former had lower initial serum lactate levels [16-18], higher central venous pressure (CVP) values (10 rather than $5 \mathrm{~mm} \mathrm{Hg}$ ) [18,19], and lower mortality rates [17-19]. The authors of these recent studies [17-19] have commented that their septic patients were seemingly less critically ill at presentation compared with those of Rivers and colleagues.

What can account for the differences between Rivers's patients and these other groups of septic patients? One suggested hypothesis is that, in the US system, some patients with sepsis might present much later because of concern about a lack of health insurance and the associated cost of care [19]. The Rivers study was done in the ED of an urban hospital (Henry Ford) in Detroit (MI, USA) and most of the patients who were included in the study may have come from a low socioeconomic background. Very recent literature from the US does emphasize the effects of socioeconomic conditions on sepsis outcome. African-American patients were found to be nearly four times more likely to be uninsured, were more likely to be admitted to the hospital through the ED and the ICU, and had higher mortality for sepsis, most probably due to disparities in disease prevention and care of pre-existing conditions before sepsis onset [20]. Outcome of Americans without insurance who are admitted to the ICU was found to be worse, possibly because 'they are sicker when they seek care' [21]. Males and African- 
Table 2

Comparison of comorbidities of the patients in studies by Rivers and colleagues [2] and Sprung and colleagues (CORTICUS) [23]

\begin{tabular}{lccc}
\hline & $\begin{array}{c}\text { Rivers et al. } \\
(\mathrm{n}=263)\end{array}$ & $\begin{array}{c}\text { Sprung et al. } \\
(\mathrm{n}=499)\end{array}$ & \begin{tabular}{c} 
Chi-square test \\
\hline Caucasian (\%)
\end{tabular} \\
Age (years) & 65.7 & 63 & 03 \\
Male/Female (\%) & $50.6 / 49.4$ & $66.5 / 33.5$ & 0.0000 \\
Hypertension (\%) & 67.3 & $37.7^{\mathrm{a}}$ & 0.0000 \\
Coronary artery disease (\%) & 25.0 & $16.9^{\mathrm{a}}$ & 0.0080 \\
Congestive heart failure (\%) & 33.4 & $6.0^{\mathrm{a}}$ & 0.0000 \\
Diabetes (\%) & $31.6^{\mathrm{a}}$ & 0.0030 \\
Chronic obstructive pulmonary disease (\%) & $11.3^{\mathrm{a}}$ & 0.0900 \\
Chronic renal failure (\%) & 15.7 & $8.7^{\mathrm{a}}$ & 0.0000 \\
Liver disease (\%) & 21.7 & $8.1^{\mathrm{a}}$ & 0.0000 \\
Neurologic disease (\%) & 23.3 & $11.7^{\mathrm{a}}$ & 0.0000 \\
Cancer (\%) & 33.0 & $16.9^{\mathrm{a}}$ & 0.0580 \\
Alcohol use (\%) & 11.4 & Not reported & \\
\hline
\end{tabular}

$a_{n}=496$. CORTICUS, Corticosteroid Therapy of Septic Shock.

Americans were also found to have a greater frequency of Gram-positive infections, possibly due to specific chronic comorbid medical conditions [22]. The patients of the Rivers study indeed seem to have a very high incidence of significant comorbid conditions. This is evident when these comorbidities are compared with those that were observed in the recent CORTICUS (Corticosteroid Therapy of Septic Shock) study [23], in which all patients had septic shock and evidence of hypoperfusion or organ dysfunction attributable to sepsis (Table 2). In addition, alcohol use, which was reported by nearly $40 \%$ of the patients in the Rivers study, was recently found to be independently associated with sepsis, septic shock, and hospital mortality among ICU patients [24].

Recently, it was pointed out that the enrollment of patients with less severe disease, who are less likely to benefit from a drug or treatment, may reduce the usefulness of randomized controlled trial findings for clinical and policy applications [25]. Similarly, it may well be that Rivers's patients had a more severe disease state and a different physiological profile than other populations of septic patients. Thus, the combination of significant comorbidities and a more delayed arrival to the ED of the Rivers patients may have led to a low cardiac output state and, in turn, to the observed very low $\mathrm{ScvO}_{2}$ values. One has to note that the use of the word 'early' in EGDT refers to the time from the patient's admission to the institution of goal-directed therapy and does not necessarily mean that the sepsis itself is of early onset. This differentiation is important since septic shock of early onset was found to be more severe than that of late onset yet was associated with better outcome [26]. The difference between early- and late-onset septic shock may therefore influence clinical trials of therapeutic agents for sepsis and should be taken into account when analyzing the results of such trials [26].

\section{Are the hemodynamic goals of the Rivers protocol suitable to guide resuscitation of all septic patients? \\ Central venous pressure}

The SSC guidelines recommend fluid resuscitation with the aim of achieving CVP values of 8 to $12 \mathrm{~mm} \mathrm{Hg}$ as the first step in the initial hemodynamic management of severe sepsis or septic shock [10] (Table 1). This recommendation is based on the practice parameters for hemodynamic support of sepsis which recommend filling pressures of between 12 and $15 \mathrm{~mm} \mathrm{Hg}$ for the optimization of cardiac output [3]. These values originate from a study that was done in 1983 in 15 patients undergoing fluid resuscitation for both hypovolemic and septic shock [27]. Since then, however, numerous articles have repeatedly shown that estimates of intravascular volume based on any given level of filling pressure do not reliably predict a patient's response to fluid administration $[28,29]$. The 2006 International Consensus Conference on hemodynamic monitoring in shock also recommended that preload measurement alone not be used to predict fluid responsiveness [30]. It did add, however, that low values of filling pressures should lead to immediate fluid resuscitation 'with careful monitoring' and that a fluid challenge should be done to predict fluid responsiveness with a goal of obtaining an increase in CVP of at least $2 \mathrm{~mm} \mathrm{Hg}$ [30]. However, a very recent study done in septic patients has shown that the 
significance of both CVP and pulmonary artery occlusion pressure (PAOP) to predict fluid responsiveness was poor and that a CVP of less than $8 \mathrm{~mm} \mathrm{Hg}$ and a PAOP of less than $12 \mathrm{~mm} \mathrm{Hg}$ predicted volume responsiveness with a positive predictive value of only about 50\% [31]. Thus, instituting aggressive fluid resuscitation in patients with low CVP values may lead to fluid overload, which may aggravate pulmonary edema, especially in those patients in whom sepsis is associated with acute respiratory distress syndrome (ARDS) and severe pulmonary dysfunction. This is also true for patients with severe sepsis but without ARDS, of whom more than half have been found to have increased extravascular lung water, possibly representing subclinical lung injury [32]. Hence, we can only join Singer's warning that rapid and large volume loads may lead to iatrogenic fluid overload and that it would be more sensible to give guidelines as to when to use more sophisticated hemodynamic monitoring to better titrate fluid input, rather than 'react post-drowning' [33].

The SSC guidelines go further to recommend that CVP values of 12 to $15 \mathrm{~mm} \mathrm{Hg}$ be achieved in mechanically ventilated patients or patients with increased intra-abdominal pressure [10] (Table 1). This recommendation is based on a review article [34] that clearly states, however, that filling pressures have a low predictive value in estimating fluid responsiveness during mechanical ventilation and that using them to guide fluid therapy can lead to inappropriate therapeutic decisions. Others recently have claimed that using the CVP to direct fluid resuscitation of patients with elevated intra-abdominal or intrathoracic pressure may place the patient at risk for under-resuscitation with resultant organ dysfunction and increased mortality [35].

\section{Central venous oxygen saturation}

Since the CVP was used as a therapeutic goal in both the standard therapy and the EGDT groups in the Rivers study, the use of a target value of $70 \%$ for the $\mathrm{ScvO}_{2}$ was, in fact, the main and only difference in the management of these two groups [2]. From the Fick formula, it can be derived that the oxygen extraction ratio is approximately equal to $\left(1-\mathrm{ScvO}_{2}\right)$ [36] and that a low ratio will normally be associated with high $\mathrm{ScvO}_{2}$ values. This is why the $\mathrm{ScvO}_{2}$ may not be a reliable parameter to direct therapy in septic patients, since a low oxygen extraction ratio is characteristic of severe sepsis. The combination of low oxygen extraction and high $\mathrm{ScvO}_{2}$ was also demonstrated in other populations of critically ill patients. Rivers and colleagues [37] have described an impairment of systemic oxygen utilization in postarrest cardiogenic shock patients. A similar impairment was found in a group of patients following cardiac surgery in whom abnormally high $\mathrm{ScvO}_{2}$ values were associated with increased serum lactate levels and increased mortality (Perz S, Uhlig S, Reinhart K, Bauer $\mathrm{M}$, unpublished data).

Further evidence for the fact that the $\mathrm{ScvO}_{2}$ values of Rivers's patients are not characteristic of all septic patients can be found in a later study of Rivers and colleagues [38], in which patients of both the standard therapy and the EGDT groups of their original study were combined and then divided into three resuscitation groups. These included (a) severe global tissue hypoxia (lactate of greater than or equal to $4 \mathrm{mmol} / \mathrm{L}$ and $\mathrm{ScvO}_{2}$ of less than 70\%), (b) moderate global tissue hypoxia (lactate of greater than or equal to $2 \mathrm{mmol} / \mathrm{L}$ and $\mathrm{ScvO}_{2}$ of less than $70 \%$ ), and (c) resolved global tissue hypoxia (lactate of less than or equal to $4 \mathrm{mmol} / \mathrm{L}$ and $\mathrm{ScvO}_{2}$ of greater than or equal to $70 \%$ ) [38]. In a recent multicenter European study [39], we have found, however, that out of 44 septic patients, $10(23 \%)$ had lactate of greater than or equal to $2 \mathrm{mmol} / \mathrm{L}$ and $\mathrm{ScvO}_{2}$ of greater than $70 \%$, a 'resuscitation group' category that simply does not exist among Rivers's patients. These findings are more in line with the recent reports of significantly higher $\mathrm{ScvO}_{2}$ values [16-18] than those observed in Rivers's patients.

Thus, for all clinical purposes, a low $\mathrm{ScvO}_{2}$ value is an important warning sign of the inadequacy of systemic oxygen delivery to meet oxygen demands. However, it does not provide information about the reason for this inadequacy, nor does it provide guidance as to the optimal therapeutic approach. On the other hand, a normal or high $\mathrm{ScvO}_{2}$ value does not rule out persistent tissue hypoxia, especially in septic patients. Therefore, very often, the $\mathrm{ScvO}_{2}$ value is unsuitable to guide resuscitation in patients with severe sepsis or septic shock, especially in the ICU (following surgery, trauma, ARDS, and so on), where low oxygen extraction ratios may be more prevalent.

\section{Conclusion}

The SSC is one of the most important developments in critical care in recent years. The people who have put this campaign together, as well as Rivers and his colleagues whose work initiated the campaign, should be congratulated for their immense life-saving contribution. Clearly, septic patients should be detected and treated as early as possible since they are at high risk for hemodynamic compromise. Many septic patients, especially those admitted to the ED, may benefit from EGDT according to the SSC guidelines, which currently are being advocated and promoted in the US and internationally in collaboration with public not-for-profit arbiters of the quality of health care [40]. However, we join the concerns that some parts of the 'bundles' of care recommended by the SSC have not been submitted to adequately powered randomized controlled trials and may actually be ineffective or even harmful [33]. Basing international treatment guidelines on the Rivers single-center study would therefore seem premature [41]. This is especially true in view of the fact that the physiological variables that are used by the SSC guidelines to direct EGDT are not suitable for all septic patients and may be misleading in many instances. We have to wait for the results of the new ongoing multicenter studies on the initial hemodynamic management of severe sepsis and septic shock and, until then, exercise caution. 


\section{Competing interests}

The author receives consulting fees for serving on the medical advisory board of Pulsion Medical Systems (Munich, Germany) and iMDsoft (Tel Aviv, Israel), and has intellectualproperty rights with Drager-Siemens (Lubeck, Germany).

\section{References}

1. Blow O, Magliore L, Claridge J, Butler K, Young J: The golden hour and the silver day: detection and correction of occult hypoperfusion within 24 hours improves outcome from major trauma. J Trauma 1999, 47:964-969.

2. Rivers E, Nguyen B, Havstad S, Ressler J, Muzzin A, Knoblich B, Peterson E, Tomlanovich M: Early goal-directed therapy in the treatment of severe sepsis and septic shock. N Engl J Med 2001, 345:1368-1377.

3. Hollenberg SM, Ahrens TS, Annane D, Astiz ME, Chalfin DB, Dasta JF, Heard SO, Martin C, Napolitano LM, Susla GM, Totaro R, Vincent JL, Zanotti-Cavazzoni S: Practice parameters for hemodynamic support of sepsis in adult patients. 2004 update. Crit Care Med 2004, 32:1928-1948.

4. Sevransky JE, Nour S, Susla GM, Needham DM, Hollenberg S, Pronovost P: Hemodynamic goals in randomized clinical trials in patients with sepsis: a systematic review of the literature. Crit Care 2007, 11:R67.

5. Dellinger RP, Carlet JM, Masur $\mathrm{H}$, Gerlach $\mathrm{H}$, Calandra $\mathrm{T}$, Cohen J, Gea-Banacloche J, Keh D, Marshall JC, Parker MM, Ramsay G, Zimmerman JL, Vincent JL, Levy MM: Surviving Sepsis Campaign guidelines for management of severe sepsis and septic shock. Crit Care Med 2004, 32:858-873.

6. Durbin CG: Is industry guiding the sepsis guidelines? A perspective. Crit Care Med 2007, 35:689-691.

7. Otero RM, Nguyen HB, Huang DT, Gaieski DF, Goyal M, Gunnerson KJ, Trzeciak S, Sherwin R, Holthaus CV, Osborn T, Rivers EP: Early goal-directed therapy in severe sepsis and septic shock revisited: concepts, controversies, and contemporary findings. Chest 2006, 130:1579-1595.

8. Russell JA: Management of sepsis. N Engl J Med 2006, 355: 1699-1713.

9. Carlet J: Early goal-directed therapy of septic shock in the emergency room: who could honestly remain skeptical? Crit Care Med 2006, 34:2842-2843.

10. Dellinger RP, Levy MM, Carlet JM, Bion J, Parker MM, Jaeschke R, Reinhart K, Angus DC, Brun-Buisson C, Beale R, Calandra T, Dhainaut JF, Gerlach H, Harvey M, Marini JJ, Marshall J, Ranieri M, Ramsay G, Sevransky J, Thompson BT, Townsend S, Vender JS, Zimmerman JL, Vincent JL: Surviving Sepsis Campaign: international guidelines for management of severe sepsis and septic shock: 2008. Intensive Care Med 2008, 34:17-60.

11. Vincent JL: Update on sepsis guidelines: what has changed? International J Int Care 2008, 15:18-21.

12. Kumar A, Roberts D, Wood KE, Light B, Parrillo JE, Sharma $S$, Suppes R, Feinstein D, Zanotti S, Taiberg L, Gurka D, Kumar A, Cheang M: Duration of hypotension before initiation of effective antimicrobial therapy is the critical determinant of survival in human septic shock. Crit Care Med 2006, 34: 1589-1596.

13. Perel A, Segal E: Management of sepsis (Letter). N Engl J Med 2007, 356:1178.

14. Krafft $P$, Stelzer H, Hiesmayr M, Klimscha W, Hammerle AF: Mixed venous oxygen saturation in critically ill septic shock patients. The role of defined events. Chest 1993, 103:900-906.

15. Vincent $\mathrm{JL}$, Gerlach $\mathrm{H}$ : Fluid resuscitation in severe sepsis and septic shock: an evidence-based review. Crit Care Med 2004, 32(Suppl):S451-454.

16. Kortgen A, Niederprüm $P$, Bauer M: Implementation of an evidence-based 'standard operating procedure' and outcome in septic shock. Crit Care Med 2006, 34:943-949.

17. Shapiro NI, Howell MD, Talmor D, Lahey D, Ngo L, Buras J, Wolfe RE, Weiss JW, Lisbon A: Implementation and outcomes of the Multiple Urgent Sepsis Therapies (MUST) protocol. Crit Care Med 2006, 34:1025-1032.

18. van Beest $P$, Hofstra J, Schultz M, Boerma E, Spronk P, Kuiper M: The incidence of low venous oxygen saturation on admission in the ICU: a multicenter observational study in the Netherlands. Crit Care 2008, 12:R33.
19. Ho BC, Bellomo R, McGain F, Jones D, Naka T, Wan L, Braitberg $G$ : The incidence and outcome of septic shock patients in the absence of early-goal directed therapy. Crit Care 2006, 10: R80.

20. Dombrovskiy VY, Martin AA, Sunderram J, Paz HL: Occurrence and outcomes of sepsis: influence of race. Crit Care Med 2007, 35:763-768.

21. Danis M, Linde-Zwirble WT, Astor A, Lidicker JR, Angus DC: How does lack of insurance affect use of intensive care? A population-based study. Crit Care Med 2006, 34:2043-2048.

22. Esper AM, Moss M, Lewis CA, Nisbet R, Mannino DM, Martin GS: The role of infection and comorbidity: factors that influence disparities in sepsis. Crit Care Med 2006, 34:2576-2582.

23. Sprung CL, Annane D, Keh D, Moreno R, Singer M, Freivogel K, Weiss YG, Benbenishty J, Kalenka A, Forst H, Laterre PF, Reinhart $\mathrm{K}$, Cuthbertson $\mathrm{BH}$, Payen D, Briegel J: Hydrocortisone therapy for patients with septic shock. N Engl J Med 2008, 358:111-124.

24. O'Brien JM Jr., Lu B, Ali NA, Martin GS, Aberegg SK, Marsh CB, Lemeshow S, Douglas IS: Alcohol dependence is independently associated with sepsis, septic shock, and hospital mortality among adult intensive care unit patients. Crit Care Med 2007, 35:345-350.

25. Greenfield S, Kravitz R, Duan N, Kaplan SH: Heterogeneity of treatment effects: implications for guidelines, payment, and quality assessment. Am J Med 2007, 120(Suppl 1):S3-9.

26. Roman-Marchant O, Orellana-Jimenez CE, De Backer D, Melot C, Vincent JL: Septic shock of early or late onset: does it matter? Chest 2004, 126:173-178.

27. Packman MJ, Rackow EC: Optimum left heart filling pressure during fluid resuscitation of patients with hypovolemic and septic shock. Crit Care Med 1983, 11:165-169.

28. Michard F, Teboul JL: Predicting fluid responsiveness in ICU patients: a critical analysis of the evidence. Chest 2002, 121: 2000-2008.

29. Vincent JL, Weil MH: Fluid challenge revisited. Crit Care Med 2006, 34:1333-1337.

30. Antonelli M, Levy M, Andrews PJ, Chastre J, Hudson LD, Manthous C, Meduri GU, Moreno RP, Putensen C Stewart T, Torres A: Hemodynamic monitoring in shock and implications for management. International Consensus Conference, Paris, France, 27-28 April 2006. Intensive Care Med 2007, 33:575-590.

31. Osman D, Ridel C, Ray P, Monnet X, Anguel N, Richard C, Teboul $\mathrm{JL}$ : Cardiac filling pressures are not appropriate to predict hemodynamic response to volume challenge. Crit Care Med 2007, 35:64-68.

32. Martin GS, Eaton S, Mealer M, Moss M: Extravascular lung water in patients with severe sepsis: a prospective cohort study. Crit Care 2005, 9:R74.

33. Singer M: The Surviving Sepsis guidelines: evidence-based ... or evidence-biased? Crit Care Resusc 2006, 8:244-245.

34. Bendjelid K, Romand JA: Fluid responsiveness in mechanically ventilated patients: a review of indices used in intensive care. Intensive Care Med 2003, 29:352-360.

35. Cheatham ML: It is time to pay attention-now more than ever! Crit Care Med 2007, 35:1629-1630.

36. Keech J, Reed RL: Reliability of $\mathrm{SvO}_{2}$ as an indicator of the oxygen extraction ratio $\left(\mathrm{O}_{2} \mathrm{ER}\right)$ demonstrated by a large patient data set. J Trauma 2003, 54:236-241.

37. Rivers EP, Rady MY, Martin GB, Fenn NM, Smithline HA, Alexander ME, Nowak RM: Venous hyperoxia after cardiac arrest. Characterization of a defect in systemic oxygen utilization. Chest 1992, 102:1787-1793.

38. Rivers EP, Kruse JA, Jacobsen G, Shah K, Loomba M, Otero R, Childs EW: The influence of early hemodynamic optimization on biomarker patterns of severe sepsis and septic shock. Crit Care Med 2007, 35:2016-2024.

39. Perel A, Maggiorini M, Malbrain M, Teboul JL, Belda J, FernándezMondéjar E, Kirov M, Wendon J: Optimal hemodynamic management according to the Surviving Sepsis Guidelines is not applicable to all ICU patients. Crit Care 2008, 12(Suppl 2):S156.

40. Eichacker PQ, Natanson C, Danner RL: Surviving Sepsis - practice guidelines, marketing campaigns, and Eli Lilly. $N$ Eng/ J Med 2006, 355:1640-1642.

41. Bellomo R, Reade MC, Warrillow SJ: The pursuit of a high central venous oxygen saturation in sepsis: growing concerns. Crit Care 2008, 12:130. 